\title{
Transumbilical endoscopic cholecystectomy in a porcine model ${ }^{1}$
}

\author{
Hong-Yi Zhu', Fu Li II, Ke-Wei Li"II, Xi-Wen Zhang' ${ }^{\mathrm{IV}}$, Jian Wang', Fu Ji ${ }^{\mathrm{VI}}$ \\ IPhD, Department of General Surgery, Renji Hospital, Shanghai Jiaotong University School of Medicine, Pu Dong, China. Conception and design of \\ the study; acquisition, analysis and interpretation of data; manuscript writing; final approval. \\ "IPDD, Department of General Surgery, Renji Hospital, Shanghai Jiaotong University School of Medicine, Pu Dong, China. Conception and design of \\ the study, analysis and interpretation of data, final approval. \\ IIIPhD, Department of General Surgery, Renji Hospital, Shanghai Jiaotong University School of Medicine, Pu Dong, China. Interpretation of \\ histopathological results, final approval. \\ ${ }^{\mathrm{IV}} \mathrm{PhD}$, Department of General Surgery, Renji Hospital, Shanghai Jiaotong University School of Medicine, Pu Dong, China. Acquisition and \\ interpretation of data, final approval. \\ ${ }^{v}$ PhD, Department of General Surgery, Renji Hospital, Shanghai Jiaotong University School of Medicine, Pu Dong, China. Final approval.

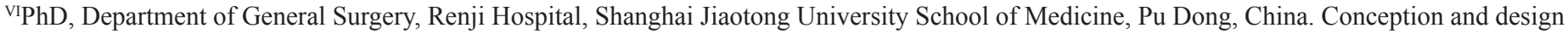 \\ of the study, final approval.
}

\begin{abstract}
PURPOSE: Natural orifice transluminal endoscopic surgery (NOTES) is a new technique. This study describes our initial experience of NOTES and investigates the feasibility of transumbilical endoscopic cholecystectomy (TUEC).

METHODS: Eight domestic pigs were submitted to TUEC. After establishment of pneumoperitoneum, a bi-channel endoscope was placed through an infra-umbilical trocar. The gallbladder fundus was lifted by a grasper. The cystic duct and artery was dissected with a flexible hook and clipped by a clip fixing device. The specimen was extracted through the infra-umbilical trocar.
\end{abstract}

RESULTS: The mean operation time was 114 minutes, ranging from 75 to 155 minutes. All the gallbladders were removed successfully. There was one case of subtotal resection, two cases of bleeding and three cases of bile leakage.

CONCLUSION: Transumbilical endoscopic cholecystectomy is feasible although it needs more support of experiments and techniques before being applied on human subjects.

Key words: Gallbladder. Cholecystectomy. Swine. 


\section{Introduction}

For a long time, the advancement of surgical techniques has continued to allow surgery to minimize invasiveness, to decrease pain and to produce a cosmetic results ${ }^{1}$. The laparoscopic techniques also make significant progress in pursuit of less resultant trauma. Langenbuch performed the first cholecystectomy in 1882 through a subcostal incision ${ }^{2}$. Mouret undertook the first laparoscopic cholecystectomy using video technology in $1987^{3}$ and laparoscopic cholecystectomy has been taken as the gold standard for gallbladder removal surgery since $1992^{4}$.

Nowadays, the use of minimally invasive surgery has increased. The modern development of minimally invasive surgery has opened up with the move from open to laparoscopic surgery by using multiple small incisions. Recent innovations have employed natural orifice transluminal endoscopic surgery (NOTES) to accomplish laparoscopic procedures. NOTES uses transvisceral access to the peritoneal cavity through the mouth, colon, urinary tract or vagina by using either rigid or flexible instruments ${ }^{5}$. NOTES may minimize surgical trauma and postoperative pain, reduce wound infection rate, shorten the length of hospital stay, hasten recovery, and result in no "visible" scars from surgery ${ }^{6,7}$. Nevertheless, NOTES is technically difficult and has been limited by concerns regarding the higher risk of abdominal infection and perforation of an organ ${ }^{8}$. Moreover, NOTES requires many special instruments 9 . Thus, for the concerns of these drawbacks, many surgeons consider the umbilicus as an alternative natural orifice due to its origin ${ }^{10,11}$. Meanwhile, the umbilicus is a well-known and standardized and direct site for access to the abdominal cavity for laparoscopic surgery ${ }^{3}$. Moreover, transumbilical endoscopic cholecystectomy (TUEC) can be performed with standard laparoscopic instruments.

Cholecystectomy is the most commonly performed laparoscopic procedure in the world and the first NOTES cholecystectomy was performed in 2007. Since then, variations have been employed in clinical practice, and NOTES cholecystectomy has been successfully performed via the transgastric route ${ }^{1}$. However, little literature was published on TUEC. For these reasons, the aim of this study is to know which advantages, difficulties and limitations are involved in performing TUEC.

\section{Methods}

The procedures were in accord with the Ethical Committee on Human Experimentation of Renji Hospital, Shanghai Jiaotong
University School of Medicine. The use of laboratory animals follow the Council for International Organization of Medical Sciences (CIOMS) ethical code for animal experimentation. Eight domestic pigs weighed 25 to $30 \mathrm{~kg}$ were presented for TUEC. The animals were fasted except water for $48 \sim 72$ hours before operation. On the day of operation, they were premeditated with intramuscular atropine $(0.04 \mathrm{mg} / \mathrm{kg})$, ketamine $(10 \mathrm{mg} / \mathrm{kg})$ and sumianxin $(0.1 \mathrm{~mL} / \mathrm{kg})$, then intubated with an endotracheal tube and received isoflurane (2\%) for maintenance of anesthesia. During the operation, scoline $(0.1 \%)$ was administered for induction of anesthesia. Electrocardiogram leads were placed and connected to the monitor to record heart rate, blood pressure and operative time.

\section{Instruments}

The instruments used in this study included endoscopic host and cold light source-OLYMPUS CV-260SL, bi-channel flexible endoscope-OLYMPUS GIF2T240 (Figure 1A), pneumoperitoneum machine-STORZ 264305 and electrotomeOLYMPUS PSD30. The flexible instruments included grasping forceps (Olymups Grasping Forceps FG-47L-1, Tokyo, Japan, Figure 1B), electrosurgical hook (Olympus Electrosurgical Knife KD-620LR, Tokyo, Japan, Figure 1C) and hemostatic clip (Olympus clip HX-610-123, Tokyo, Japan, Figure 1D).

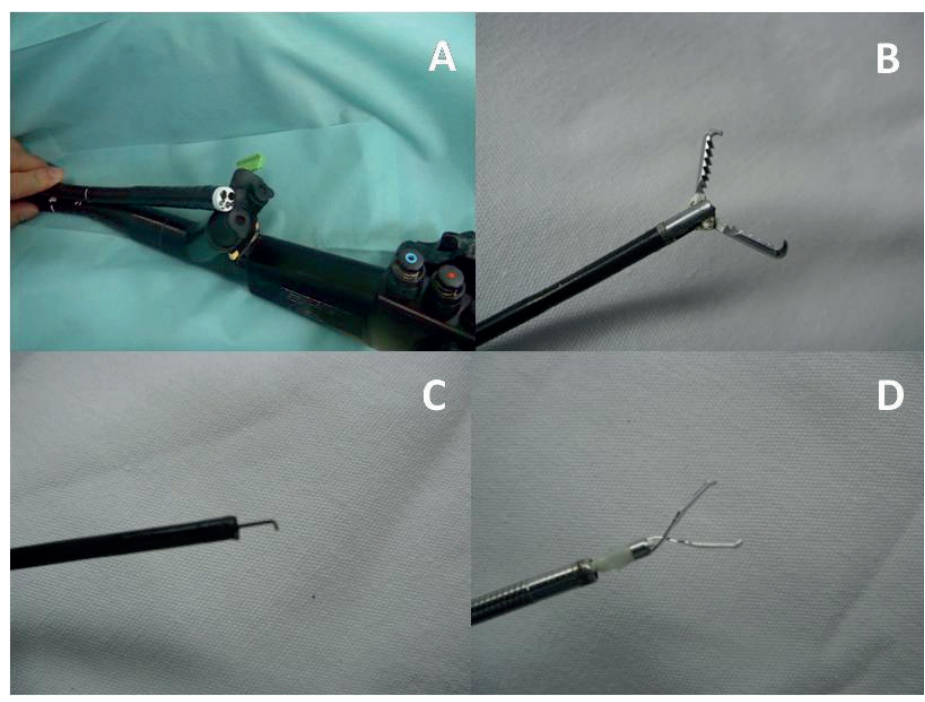

FIGURE 1 - The main surgical instruments used in TUEC. The instruments included endoscopic host and cold light source-OLYMPUS CV-260SL, bi-channel flexible endoscope-OLYMPUS GIF2T240 (A), pneumoperitoneum machine-STORZ 264305, and electrotomeOLYMPUS PSD30. The flexible instruments included grasping forceps (B), electrosurgical hook (C) and hemostatic clip (D). 


\section{Surgical procedures}

After establishment of pneumoperitoneum by $\mathrm{CO}_{2}$, the bi-channel endoscope was placed through a $1.5 \mathrm{~cm}$ infraumbilical trocar. The abdominal cavity was inspected and a fine grasper of $2 \mathrm{~mm}$ diameter was inserted through a $5 \mathrm{~mm}$ trocar on the right upper abdomen. The surgeon performed the dissection by manipulating the control knobs on the endoscope, and the first assistant maintained the position of the endoscope while retracting the gallbladder by grasping its fundus through the $5 \mathrm{~mm}$ port. A second assistant stood on the opposite side of the table and controlled the flexible endoscopic instruments, which included the hook and the forceps. After the left side was elevated 30 degree and the fundus of the gallbladder was lifted by the grasper, the vascular and cystic duct of gallbladder was exposed. The flexible grasper and electrosurgical hook were passed through the endoscopic channels to separate the serosa on both sides of the cystic duct and artery, which was cut off after clipped by three hemostatic clips, leaving two clips on the nub (Figure 2A). The gallbladder was peeled off from the liver by an electrosurgical hook (Figure 2B). The specimen was extracted through the infra-umbilical trocar (Figure 2C). The infra-umbilical incision was closed by subcutaneous stitches.

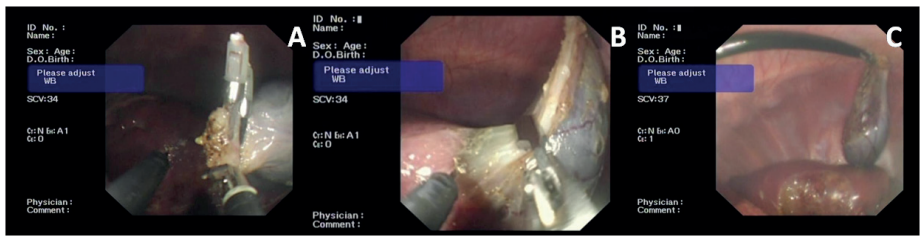

FIGURE 2 - The surgical procedures of TUEC. The flexible grasper and electrosurgical hook were passed through the endoscopic channels to separate the serosa on both sides of the cystic duct and artery, which was cut off after clipped by three hemostatic clips, leaving two clips on the nub (A). The gallbladder was peeled off from the liver by an electrosurgical hook (B). The specimen was extracted through the infra-umbilical trocar (C). The infra-umbilical incision was closed by subcutaneous stitches.

\section{Postoperative management}

Eight animals were sacrificed postoperatively immediately. Postmortem examinations of the specimen was carried out, and the blood and bile in the operative region were also investigated.

\section{Results}

All procedures were completed without conversion to an open operation or introduction of any additional trocars. The mean operative time was $114 \mathrm{~min}$, ranging from 75 to $155 \mathrm{~min}$. All the gallbladders were removed successfully. There was one case of subtotal resection, two cases of bleeding from the gallbladder bed and stopped by electric coagulation, one case of bleeding from the artery and stopped by clip, three cases of bile leakage including two cases of perforation of gallbladder during dissection and one case of cystic gall duct clipped incompletely. Postmortem examination revealed that the clips on the cystic duct and artery were secure, without bleeding and bile leakage (Table 1).

TABLE 1 - Operation situation.

\begin{tabular}{|c|c|c|c|c|c|}
\hline Case & Time & & Bleeding & & $\begin{array}{c}\text { Reason of } \\
\text { Bile leakage }\end{array}$ \\
\hline & $(\min )$ & Site & Volume & Solution & \\
\hline $1 *$ & 86 & Artery & $80 \mathrm{ml}$ & Clipped & $\begin{array}{l}\text { Broken by } \\
\text { grasping } \\
\text { forceps }\end{array}$ \\
\hline 2 & 75 & $\begin{array}{c}\text { Gallbladder } \\
\text { bed }\end{array}$ & $30 \mathrm{ml}$ & Coagulated & / \\
\hline 3 & 122 & l & / & / & $\begin{array}{c}\text { Heat exchange } \\
\text { of electrosurgical } \\
\text { hook }\end{array}$ \\
\hline 4 & 155 & $\begin{array}{c}\text { Gallbladder } \\
\text { bed }\end{array}$ & $5 \mathrm{ml}$ & Coagulated & / \\
\hline 5 & 125 & l & / & / & $\begin{array}{c}\text { Cystic gall } \\
\text { duct clipped } \\
\text { incompletely }\end{array}$ \\
\hline 6 & 123 & / & l & l & / \\
\hline
\end{tabular}

*Case 1: Gallbladder subtotal resection

\section{Discussion}

NOTES has hitherto been performed in several institutions. Swain et al. ${ }^{12}$ report the experimental data of transgastic cholecystectomy on swine in 2004. Marescaux et $a l .{ }^{13}$ report their first transvaginal endoscopic cholecystectomy in Strasburg on April 2007, which is the first real clinical NOTES. Niu et al. ${ }^{14}$ has finished 43 cases of transvagial laparoscopically assisted endoscopic cholecystectomy since May 2009 in China. In recent years, Julianov et al. ${ }^{15}$, Hong et al. ${ }^{16}$ and Zhu et al. ${ }^{17}$ report successful cases of transumbilical cholecystectomy due to the difficulties of procedures in NOTES. However, they finish the operation with the rigid laparoscopic instrument which is exactly so-called single-incision laparoscopic skill. Palanvielu et 
$a l .{ }^{18}$ first present a hybrid technique for cholecystectomy in 2008, namely the combination of a flexible transumbilical bi-channel endoscope and a 3-mm rigid transcutaneous trocar placed in the right hypochondrium for liver retraction. It seems more promising for clinical application than former standard NOTES.

Currently, the natural orifices for NOTES include stomach, vagina, colon, anus, bladder and others. Surgical risks of NOTES are evident when the visceral incision is closed and severe postoperative complications such as abdominal abscess, gastrointestinal leakage, and bleeding appeared. Transumbilical operation is much safer and can also reach the effect of minimally invasive surgery with no scar. Therefore, we chose the umbilical approach to accomplish the cholecystectomy. The result of this study proved that TUEC was feasible. However, NOTES also presents certain disadvantages, such as an unstable surgical platform that required multiple operators manipulating the endoscope and controlling the wheels in conjunction with endoscopic instruments ${ }^{19}$. Our operation time was longer than traditional laparoscopic operations and not shortened obviously during the whole experiment. Thus, there must be a long learning curve. The operator should accumulate lots of experience to grasp this technique exactly.

Surgeons get used to perform laparoscopic surgery in a larger view. However, the circular endoscopic view is not stable for the surgeons because of the difficult control of the movement of the endoscope. The surgeon with the basis of endoscope experience should be able to adapt quickly. Some reports ${ }^{20}$ show that multiple cameras can be used to obtain suitable view. For example, "R" type endoscope whose second band can be locked so that endoscope can be fixed in the right position and the surgeon can adjust the first bend to operate.

In our study, the additional trocar must be inserted through a small skin incision on the right upper abdomen where the grasping forceps was placed to expose the operation site. This step cannot be ignored with current instruments. Leroy et al. ${ }^{21}$ finish the first per-anal sigmoidectomy in 2008, during the operation he put a bar magnet inside the sigmoid colon, while putting another bar magnet on the abdomen wall to draw colon to achieve good surgical exposure. This method may be considered to be used in TUEC.

However, the surgical instruments we used were still simple, and the grasping forceps and electrosurgical hook were still used in this study. Since TUEC was more difficult than laparoscopic surgery, bleeding or bile leakage may happen in the early stage ${ }^{22}$. In this study, there was 1 case that the gallbladder was broken by the grasping forceps, which was attributed to the shortage of the instruments. Thus, all the instruments, including those used for the exposure of operative field, such as grasping forceps, hemostatic clips and suction, should be improved further in order to make operation convenient. The right way to deal with the cystic duct and artery was the most important step during the operation $^{23}$. Otherwise, once bleeding or bile leakage happened, it would bring a lot of troublesome, even lead to conversion to an open operation. Because the cystic duct and artery of the pigs are longer than those of human, it can be exposed easily. However, their anatomical position are too closed to be separated. We separated the serosa on both sides of the cystic duct and artery as much as possible and clipped them together exactly by three hemostatic clips, leaving two clips on the nub. While peeling the gallbladder off by using electrosurgical hook, the operator should distinguish the anatomic levels to avoid bleeding from gallbladder bed, and perforation of the gallbladder wall. Once bleeding, the operator should distinguished the site in time and clip or fulgurate it in order to stop the bleeding. There are several trocars in traditional laparoscopic surgery. Suction and operation can be performed at the same time. However, there was only one free trocar in TUEC. Bleeding and bile leakage will greatly affect the view which maybe result in biliary injury. We put the suction through the trocar on the right upper abdomen to suck the bile or blood away. If the bleeding volume was more, additional trocars were introduced to perform the suction and hemostasis. Of course, the open operation was still one of choices which make the operation safe.

We propose that TUEC is entirely feasible while it needs improved equipment and more skill. In recent years, as NOTES still has several technical difficulties to be solved, new concepts of minimally invasive surgery are proposed, including laparoendoscopic single-site surgery (LESS) and 'Da Vinci' robotic surgery, which have been applied on human subjects and developed rapidly. Hernadez et al. ${ }^{24}$ follow 150 patients undergoing LESS cholecystectomy and consider the learning curve of LESS cholecystectomy is definable, short and safe, and the key point of the surgery is similar to multi-incision surgery. Furthermore, another new technique 'Da Vinci Robot', which could help surgeons accomplish various complicated operations such as resection of gastric carcinoma, right hemicolectomy, pancreatoduodenectomy and others. Although it is feasible in our experiment, the future of TUEC is uncertain because of its technical difficulties and the existing problems compared to LESS. 


\section{Conclusion}

Transumbilical endoscopic cholecystectomy is feasible although it needs more support of experiments and techniques before being applied on human subjects.

\section{References}

1. Pollard JS, Fung AK, Ahmed I. Are natural orifice transluminal endoscopic surgery and single-incision surgery viable techniques for cholecystectomy? J Laparoendosc Adv Surg Tech A. 2012;22(1):114.

2. van Gulik T. Langenbuch's cholecystectomy, once a remarkably controversial operation. Neth J Surg. 1986;38(5):138-41.

3. Vilallonga R, Barbaros U, Sumer A, Demirel T, Fort JM, Gonzalez O, Rodriguez N, Carrasco MA. Single-port transumbilical laparoscopic cholecystectomy: A prospective randomised comparison of clinical results of 140 cases. J Minim Access Surg. 2012;8(3):74-8.

4. Oruc MT, Ugurlu MU, Boyacioglu Z. Transumbilical multipleport laparoscopic cholecystectomy using standard laparoscopic instruments. Minim Invasive Ther Allied Technol. 2012;21(6):4238 .

5. Autorino R, Yakoubi R, White WM, Gettman M, De Sio M, Quattrone C, Di Palma C, Izzo A, Correia-Pinto J, Kaouk JH, Lima E. Natural orifice transluminal endoscopic surgery (NOTES): where are we going? A bibliometric assessment. BJU Int. 2013;111(1):116.

6. Garud SS, Willingham FF. Natural orifice transluminal endoscopic surgery. Endoscopy. 2012;44(9):865-8.

7. Markar SR, Karthikesalingam A, Thrumurthy S, Muirhead L, Kinross J, Paraskeva P. Single-incision laparoscopic surgery (SILS) vs. conventional multiport cholecystectomy: systematic review and meta-analysis. Surg Endosc. 2012;26(5):1205-13.

8. Hu H, Zhu J, Wang W, Huang A. Optimized transumbilical endoscopic cholecystectomy: a randomized comparison of two procedures. Surg Endosc. 2010;24(5):1080-4.

9. Wang J, Zhang L, Wu W. Current progress on natural orifice transluminal endoscopic surgery (NOTES). Front Med. 2012;6(2):187-94

10. Sajid MS, Ladwa N, Kalra L, Hutson KK, Singh KK, Sayegh M. Single-incision laparoscopic cholecystectomy versus conventional laparoscopic cholecystectomy: meta-analysis and systematic review of randomized controlled trials. World J Surg. 2012;36(11):2644-53.

11. Fransen S, Stassen L, Bouvy N. Single incision laparoscopic cholecystectomy: a review on the complications. J Minim Access Surg. 2012;8(1):1-5.

12. Park PO, Bergstrom M, Ikeda K, Fritscher-Ravens A, Swain P. Experimental studies of transgastric gallbladder surgery: cholecystectomy and cholecystogastric anastomosis (videos). Gastrointest Endosc. 2005;61(4):601-6.

13. Marescaux J, Dallemagne B, Perretta S, Wattiez A, Mutter D, Coumaros D. Surgery without scars: report of transluminal cholecystectomy in a human being. Arch Surg. 2007;142(9):823-6.

14. Niu J, Song W, Yan M, Fan W, Niu W, Liu E, Peng C, Lin P, Li P, Khan AQ. Transvaginal laparoscopically assisted endoscopic cholecystectomy: preliminary clinical results for a series of 43 cases in China. Surg Endosc. 2011;25(4):1281-6.

15. Julianov A, Karashmalakov A. Transumbilical laparoscopic cholecystectomy. Arch Surg. 2010;145(4):402-3.

16. Hong TH, You YK, Lee KH. Transumbilical single-port laparoscopic cholecystectomy: scarless cholecystectomy. Surg Endosc. 2009;23(6):1393-7.

17. Jiang Fan Z, Ying Zhang M, Jin Ling Y, Hai H. Transumbilical endoscopic cholecystectomy with the trichannel trocar technique: a porcine feasibility study. Surg Innov. 2008;15(2):95-9.

18. Palanivelu C, Rajan PS, Rangarajan M, Parthasarathi R, Senthilnathan P, Praveenraj P. Transumbilical flexible endoscopic cholecystectomy in humans: first feasibility study using a hybrid technique. Endoscopy. 2008;40(5):428-31.

19. Comitalo JB. Laparoscopic cholecystectomy and newer techniques of gallbladder removal. JSLS. 2012;16(3):406-12.

20. Bardaro SJ, Swanstrom L. Development of advanced endoscopes for Natural Orifice Transluminal Endoscopic Surgery (NOTES). Minim Invasive Ther Allied Technol. 2006;15(6):378-83.

21. Leroy J, Cahill RA, Asakuma M, Dallemagne B, Marescaux J. Single-access laparoscopic sigmoidectomy as definitive surgical management of prior diverticulitis in a human patient. Arch Surg. 2009;144(2):173-9.

22. Song TJ, Seo DW, Kim SH, Park do H, Lee SS, Lee SK, Kim MH. The performance of multiple transgastric procedures using the natural orifice transluminal endoscopic surgery technique: is pure NOTES satisfactory? Gut Liver. 2012;6(4):457-63.

23. Voermans RP, van Berge Henegouwen MI, Bemelman WA, Fockens P. Hybrid NOTES transgastric cholecystectomy with reliable gastric closure: an animal survival study. Surg Endosc. 2011;25(3):728-36.

24. Hernandez J, Ross S, Morton C, McFarlin K, Dahal S, Golkar F, Albrink M, Rosemurgy A. The learning curve of laparoendoscopic single-site (LESS) cholecystectomy: definable, short, and safe. J Am Coll Surg. 2010;211(5):652-7.

\section{Correspondence:}

\section{Ke-Wei Li}

General Surgery, Renji Hospital

Shanghai Jiaotong University School of Medicine

1630 Dong Fang Road, Pu Dong

Shanghai 200127, China

Phone: +86-13003232119

Fax: $+86-13003232119$

keweili@hotmail.com

Received: July 25, 2013

Review: Sept 23, 2013

Accepted: Oct 21, 2013

Conflict of interest: none

Financial source: none

${ }^{1}$ Research performed at Renji Hospital, Shanghai Jiaotong University School of Medicine, Pu Dong, China. 